\title{
Maternal perceptions of supervision in pre-school age children: \\ A qualitative approach to understanding differences between families living in affluent and disadvantaged areas
}

\begin{abstract}
Aim: To explore maternal perceptions of supervision and childhood unintentional injury in order to develop understanding and explanation for differences in unintentional injury rates between an advantaged and disadvantaged area.
\end{abstract}

Background: Unintentional injury is the second cause of mortality and a significant cause of morbidity in the 0-4 year age group. Children living in socio-economic disadvantage are at a greater risk of unintentional injury than their more affluent counter parts.

Methods: Qualitative study using semi-structured interviews; content data analysis was undertaken. Participants included thirty seven mothers with a child aged less than five years; 16 living in an area of disadvantage (and high rate of childhood unintentional injury) and 21 living in an advantaged area (and low rate of childhood unintentional injury).

Findings: Parents in both areas described the importance of parental supervision in reducing child unintentional injury risks. Parents in both areas used listening as a supervision strategy. Parents in both areas described how 'when the child goes quiet' that is a cue for them to make a visual check on the child. Listening was used more for boys than girls in both areas, but parents in the advantaged area used listening as a supervision strategy more frequently than those in the disadvantaged area. Parents described supervision strategies as being shaped by child character and age rather than child gender. Parents in both areas described similar strategies for managing distractions. An important difference was found with regard to older siblings; parents living in the advantaged area described older siblings as an injury risk to younger children. Parents in the disadvantaged area described older siblings as providing some supervision for younger children. Parents living in disadvantaged circumstances may face greater challenges with regard to supervision than parents living in advantaged circumstances and this may partly explain differences in injury risk.

KEY WORDS: Parental supervision: Childhood unintentional injury; Qualitative study; Parental perceptions; Injury prevention 


\section{Introduction}

Unintentional injury is the second leading cause of mortality and a significant cause of morbidity within the 0-4 year age group (ONS 2011). In this age group unintentional injuries are most likely to occur at home as this is where children often spend most of their time (DOH 2002). Injuries place a considerable burden on the National Health Service; each year unintentional injury results in approximately 2 million children attending emergency departments in the UK and half of these injuries occurred within the home (ACAHC 2007).

Childhood unintentional injury is unevenly distributed across society. There are wide inequalities between social groups in relation to child mortality and morbidity (Towner 2002). Children living in circumstances of socio-economic disadvantage are more likely to experience unintentional injury than their more affluent counterparts. The social gradient for deaths relating to unintentional injury is greater than for any other cause of death (Edwards, Roberts et al. 2006). Boys are more likely to suffer an unintentional injury than girls (Towner, Dowswell et al. 2001).

Parental supervision is an important factor in reducing the risk of unintentional injuries within the home (Schwebel and Bounds 2003; Morrongiello, Ondejko et al. 2004; Morrongiello, Corbett et al. 2006). Parental perceptions that supervision will reduce the risk of unintentional injury are important (Sparks, Craven et al. 1994; Garling and Garling 1995).

One of the difficulties related to parental supervision is that there is not one universal definition agreed by parents, practitioners and researchers (Morrongiello 2005). Morrongiello defines supervision as "behaviours that index attention (watching and listening) in interaction with those that reflect state of readiness to intervene with both types of behaviour judged over the index of continuity and proximity" (Morrongiello 2005). This definition combines parent behaviour of watching and listening with knowledge of child whereabouts and activity, combined with parental readiness to intervene to prevent a child undertaking an unsafe activity. This, Morrongiello argues, results in maximal supervision (Morrongiello 2005). In situations where the child is out of reach of the parent, the next optimal supervision strategy is verbal direction to intervene to prevent the child undertaking an unsafe activity. This, Morrongiello argues, is a lower level of supervision (Morrongiello 2005). Other factors that may be important to consider are the age of the child, the character of the child, and the living conditions of the home environment.

An extension of the definition by Morrongiello (Morrongiello 2005) is to consider three attributes of supervision; parents attention to their child's behaviour, the proximity of the parent to their child and continuity of supervision(Schwebel and Kendrick 2009). Attention encompasses watching and listening to the child's activity and behaviour and is a spectrum from full undisrupted attention to totally absent attention. Proximity refers to parents' proximity to the child. Continuity of supervision is a spectrum from constant uninterrupted visual and listening to intermittent visual and listening to the child. The difficulties lie in how to describe and measure each attribute for research purposes (Schwebel and Kendrick 2009). 
A parent's ability to provide direct and constant supervision may be impaired by a number of factors including the requirement to complete household tasks (Roberts, Smith et al. 1995; Boles and Roberts 2008). There is some evidence to suggest that boys and girls may receive differential supervision from parents (Morrongiello and Hogg 2004). The presence of an older sibling may also increase the risk of injury to a younger child. This may be impaired parental supervision, due to the number of children in the household, or because an older child provides some supervision to a younger sibling (Nathens, Neff et al. 2000; Morrongiello, MacIsaac et al. 2007).

There has been little exploration with regard to parental supervision and living in circumstances of disadvantage, however this may provide some potential explanation for differential injury rates. The aim of this qualitative study was to gain an understanding of maternal perceptions of supervision and to explore possible differences in supervision between families living in an advantaged and disadvantaged area.

The two areas included in this study are St Ann's ward and Wollaton West ward in Nottingham, UK. St Ann's ward is one of the most deprived wards within Nottingham city, with a high level of transience and an area where significant social problems exist. Social problems within the ward include a high number of people living on low incomes, poor quality housing, unemployment and high rates of crime. St Ann's has high levels of poor health, a lower life expectancy and higher injury rates than other wards in Nottingham and much higher than the national average (Nottingham Primary Care Trust Annual Health Report 2003-4). By comparison Wollaton west ward has a low level of transience and mainly consists of people working in professional employment, good quality privately owned homes, and a low rate of child injury.

\section{Methods}

\section{Recruitment}

The first stage involved inviting health visitors to assist with the recruitment of parents in each of the wards. Three health visitors, in each ward, were asked to send a participant recruitment pack to 50 parents. To ensure that cases were selected systematically, health visitors were asked to select every other child from their caseload within a specified age group. In each ward one health visitor selected 50 cases where the child was aged 0-11 months, the second heath visitor selected 50 children aged 1223 months and the third selected 50 children aged 24-48 months. In the instance where a health visitor had a total of 50 children in their specified age bracket they were asked to select all of these households. Parents who were interested in taking part where asked to return a reply slip with their contact details in a pre-paid envelope to the researcher. The researcher then contacted them by telephone, explained the purpose of the study in greater detail and answered any questions about participation in the study. If they agreed to take part in the study a date and time was arranged for the researcher to visit them at their home to in order to carry out the interview. The aim was to recruit 21 parents in each ward, seven with a child aged 0-11 months, seven with a child aged 1223 months and seven with a child aged 24-48 months. In order to complete the St Ann's sampling frame additional recruitment took place via a mother and toddler group and via a children's centre in St Ann's. 


\section{Data Collection}

Data collection included in-home interviews that lasted on average approximately 40 minutes. One interview took place at the St Ann's Sure Start centre, Nottingham, at the request of the participant. All interviews were conducted with the mother; fathers were present in two of the interviews. Interviews were conducted between January and April 2008.

A semi-structured interview schedule was developed, piloted with two families and adapted accordingly. The interview guide included questions covering; perceptions of injury risks within the home and how they try to prevent them, who is mainly responsible for looking after the children, do they have any older children and do they help with looking after younger children, daily routines and supervision practices, how they manage supervision when they are tired, how they manage supervision when they feel they need a break. The interview guide was developed following a review of literature (Sparks, Craven et al. 1994; Garling and Garling 1995; Roberts, Smith et al. 1995; Nathens, Neff et al. 2000; Morrongiello, Ondejko et al. 2004; Morrongiello, Corbett et al. 2006; Morrongiello, MacIsaac et al. 2007).

Interviews were audio taped, with written and signed consent, and transcribed. During transcription names were changed to protect anonymity.

\section{Data analysis}

The interview data was transcribed verbatim. The data was explored for emerging themes, the data was read and re read drawing out themes and sub themes (Silverman 2000). The coding process of the interviews included both confirming and disconfirming cases (Murphy, Dingwall et al. 1998). Three researchers read the transcripts noting significant themes. Following this the researchers discussed the main emerging themes and sub themes and developed coding categories. A definition for the themes was then agreed. These themes were used to code the data using the computer software package Nvivo version 1 . As the data was analysed any emerging themes were applied to previously coded data. When all data had been coded, themes were counted in order to identify patterns within the data.

\section{Findings}

\section{Response rates and participant characteristics}

In Wollaton west $33(22 \%)$ responses were received from the first mailing of 150 recruitment packs. From the 33 responses received, 21 parents were randomly selected to take part in the study. In St Ann's $13(8 \%)$ responses were received from a first and reminder mailing of 150 recruitment packs and 10 parents agreed to be interviewed. Recruitment via a mother and toddler group and at the Sure Start children's centre resulted in seven parents agreeing to be interviewed, one of whom withdrew prior to interview. The total number of interviews undertaken was 21 in Wollaton west and 16 in St Ann's. When 16 parents had been recruited in St Ann's the decision was taken to 
cease recruitment due to data saturation and resource and time constraints. The characteristics of participants in the two areas are shown in table 1.

As the interviews were conducted in the homes of participants it was possible for the interviewer to observe the difference between the two areas in relation to living environments. As shown in table 1, the majority of St Ann's parents were living in council or privately rented accommodation. These homes were of poor quality and in greater need of repair. By contrast Wollaton west parents were all living in privately owned homes that were well maintained. As shown in table 1, the maternal age of mothers living St Ann's was much lower than for mothers in Wollaton West.

\section{Key themes}

Five key themes emerged from the data; perceptions of supervision and injury risk, listening as a supervision strategy, supervision practices shaped by child character, supervision strategies when multi-tasking, older children and injury risk to younger siblings.

\section{Perceptions of supervision and injury risk}

Parents living in both areas $10(62.5 \%)$ parents in St Ann's and 17 (80.9\%) in Wollaton west described how a lack of supervision is likely to increase the potential for injury risk. Parents living in both areas described a need to be constantly vigilant and aware of where the child is and what the child is doing. Parents living in both areas held similar perceptions about the consequences of not supervising adequately being an injury risk to their child.

I think you have to keep an eye on the kid. If you are not keeping an eye on the kid and the kid is upstairs and you are down stairs then definitely you have to expect something happening. SA 8 Girl 12-23 months

\section{Listening as a supervision strategy}

Parents in both areas described using listening as a supervision strategy. Parents living in both areas described how if their child goes quiet and the child is not in their vision that is a signal that something is wrong and that is the cue that they use to then go and check on their child. Listening was used as a supervision strategy for boys more than girls in both areas and was used more in Wollaton west than in St Ann's.

When he's quiet you know he's up to summat. If he's quiet I say [childs name] and if he don't answer I go and check on him to see what he's up to. SA 14 Boy 12-23 months

If I put him one room and run to another room to get something yes you are listening all the time, because he's babbling away. If he stops you would be straight in to see why or if the babbling changes you are constantly listening to what they are doing. W10 Boy 12-23 months

\section{Supervision practices shaped by child character}


When describing supervision practices and how these may vary, parents living in both areas described how it was the character of the child that impacts on injury risk taking behaviour and this, in turn, shapes their supervision strategies.

I think it's just when the child you've got is very inquisitive and into everything whereas our first child wasn't like that. So a different child you know it's different dangers and things.SA16 Boy 12-23 months

It depends on the individual child. Because I know in the past when I've looked after other people's children if I said you mustn't touch that because it's hot and you'll burn yourself, I know that my daughter would heed that advice but there are some children that wouldn't heed that advice at all and would still go and touch it. W19 Girl 12-23 months

\section{Supervision strategies when multi-tasking}

Parents living in both areas described similar tasks which impaired their ability to supervise their child. Parents often described cooking/preparing a meal and getting ready in the morning as times when their supervision was most impaired. Parents living in both areas also implemented similar strategies to try to minimise injury risks when their ability to supervise is impaired. Examples included putting on the television while they cook, moving between rooms, placing the child in a safe place or having the child assist with the task.

That probably is when you let your guard slip when you think I just need to do this I'm just gonna nip upstairs or nip outside to peg the washing out. And you do and that's when you forget how young and vulnerable they are. W9 Girl 0-11 months Boy 24-48 months

Say tea time. You know when I'm trying to wash up and cook the food then yeah ...Like when I'm doing summut and he can't do it I just make sure loads of his toys are still out so he can have different toys so he don't get bored and then he just sits and plays. SA 14 Boy 12-23 months

\section{Older children and injury risk to younger siblings}

There are important differences in the way parents' living in the two areas described older children and injury risk to a younger child. None of the parents living in St Ann's described older children as posing an injury risk to a younger child, whereas parents in Wollaton west did consider older children in this way. This may be through rough play or leaving small pieces from toys in the vicinity of the younger child that present a choking hazard. There are examples from the interviews of parents living in Wollaton west ward describing near miss incidents where older children have resulted in injury risk to the younger child not when they were supervising but when both children were left in the same room and the mother was not present.

Of course you also have the additional accident factor of older child. I did come in once and said what have you done and she'd buried him in the blankets [...]We came in and there was this blanket and we were like where is [boys name] and he was 
under the blanket and he was only about 5 months old. He was getting quite hot under there that was a bit scary wasn't it. W5 Girl 24-48 months Boy 12-23 months

Parents in St Ann's who were parenting alone, describe how older children can provide some level of supervision to the younger child. Married couples living in St Ann's did not describe older siblings as providing supervision to the younger child. In contrast there are no examples in Wollaton west of parents describing older siblings as supervisors of younger siblings (there was only one mother who was parenting alone in Wollaton west).

I do have a bit of a lie in my bed. Cos I've got my older one (age 6) he will come downstairs with the younger one and they'll probably just watch cartoons SA4 Boy 2448 months

\section{Discussion}

There has been little research undertaken that has explored the attitudes, perceptions and experiences of parents using a qualitative methodology. In particular, few qualitative studies have explored such differences by comparing parents living in an area of disadvantage with parents living in an area of relative affluence (Sparks, Craven et al. 1994).

The recruitment methods used which provided health visitors with specific criteria, ensured that bias was not introduced by health visitors selecting families to invite to the study. The use of additional recruitment strategies in St Ann's ensured that sufficient participants were recruited to complete data collection and to gather data from a 'hard to reach' group. Although only 16 participants were recruited in St Ann's, as data saturation was reached, this did not negatively impact on the findings. The use of quota sampling ensured an even distribution of child ages between the wards (Patton 1980). The interview process collected data that included descriptions of personal experiences and previous injury events from parents living in both wards. Perfect world scenarios were not given by parents in the interviews. They did not describe a situation where their child plays and never has an injury or near miss event and that they listen to all safety advice and implement it all. This is what they may have tried to describe if parents had felt uncomfortable or judged and had wanted to describe scenarios of what they 'should' do.

Parents were comfortable to provide descriptions based on the reality of their everyday lives. They described injury near misses and actual events, difficulties with keeping children safe and their perceptions of safety equipment and safety advice. A further strength of this study is that a systematic method was used during the data analysis process. Three researchers identified and discussed themes in the data to avoid subjectivity (Pope, Ziebland et al. 2000). The data was also explored for descriptions that did not fit into the main themes (Murphy, Dingwall et al. 1998).

The limitations of the study are that it is possible that the parents who agreed to take part in the study had a particular interest in or were motivated by the aims of the study or child safety in general. The data may, therefore, not be representative of all parents living in the two areas (Bowling 2002). It is not appropriate to make generalisations to the wider population from the findings of this study. However, it is possible to transfer some of the findings to similar groups of people who live in similar circumstances. 
The findings did not reveal differences between parents living in the two areas with regard to perceptions of the importance of parental supervision. Parents living in both areas described how a lack of parental supervision may result in an increased unintentional injury risk to their child. Parents from both areas described how it is necessary to be constantly aware of where the child is and what the child is doing.

Similar findings were revealed, for both areas, with regard to how parents supervise when they are distracted, or engaged in performing a task that impairs their ability to supervise. Parents, living in both areas, described strategies to keep their child safe during these times. Examples included putting on the television or DVD to keep the child occupied, moving between rooms or letting the child assist with the task.

Parents living in both areas described how the child going quiet is a cue for them to go and visually check on the child. The findings show that parents living in both areas described using listening as a supervision strategy more for boys than girls. Parents living in Wollaton west described using listening as a supervision strategy more than parents living in St Ann's for both boys and girls. Parents in St Ann's described a need for constant visual supervision.

Some parents, living in both areas, described perceived gender differences in similar ways; that boys are at a greater risk of unintentional injury than girls. This was thought to be due to boys being more boisterous, more physical and engaging in rough play more than girls.

The findings reveal, that parents living in both areas described the character of the child rather than the gender of the child as shaping child risk taking behaviour and consequently the way that parents supervised.

A difference between the areas relates to supervision and older siblings. In families in St Ann's, where a mother was parenting alone and an older sibling was present, the mothers described how the older child would provide some supervision of the younger child. This contrasts with descriptions in Wollaton west where mothers described older children as an unintentional injury risk to the younger child.

Parental supervision has been shown to be perceived by parents as reducing the risk of unintentional injury to their children (Sparks, Craven et al. 1994; Garling and Garling 1995; Roberts, Smith et al. 1995). Our study found that parents living in both areas described the importance of parental supervision to minimise unintentional injury risks to children; differences between the areas in terms of attitudes toward supervision do not provide an explanation for differential injury rates. As identified in other studies parents acknowledge that there are times during the day when their ability to supervise may be impaired, mainly due to additional household tasks that they are required to undertake (Roberts, Smith et al. 1995; Boles and Roberts 2008). Parents living in both areas describe how they try to manage these times with strategies aimed at occupying the child to prevent them from engaging in risk taking behaviour.

Living in rented accommodation is associated with an elevated risk for injury as is living in poor quality accommodation and transient housing (Roberts, Smith et al. 1995; Carr 2005; Kendrick, Mulvaney et al. 2005; Brussoni, Towner et al. 2006; Olsen, Bottorff et 
al. 2008). Children living within an environment where there is limited space for safe play both indoors and outdoors are also at an increased risk of unintentional injury (Olsen, Bottorff et al. 2008). St Ann's families that live in a home that is in greater need of repair may face a greater requirement to provide more constant and vigilant supervision than parents in Wollaton west who live in homes of good repair and quality.

The maternal age was very different between the areas; mothers living in the disadvantaged area had a lower maternal age than mothers living in the advantaged area. Low maternal age is also a factor associated with increased injury risk (O'Connor, Davies et al. 2000; Kendrick, Mulvaney et al. 2005). Combined with living in poor quality rented accommodation this may provide some explanation for the difference in injury rates between the areas.

Listening was described as a supervision strategy in both areas; however it was used more in Wollaton west. There are two possible reasons for this finding. One explanation may be associated with social desirability bias (Bowling 2002). Parents in St Ann's may have been more reluctant to reveal that they use listening as a supervision strategy than parents in Wollaton west. This may be linked with the fear of talking to professionals for fear of the consequences (Brannan 1992; Mull, Agran et al. 2001; Hendrickson 2008; Olsen, Bottorff et al. 2008).

Alternatively the difference may be linked to the home environment and parents in Wollaton west feel more relaxed that they have the safety measures in place, to use listening as a strategy. In St Ann's parents may be keeping their child within their vision as far as is possible in order to minimise injury risks.

Epidemiological data have well established fact that boys experience more injuries than girls for all injury mechanisms (ONS 2009). Other studies have identified differences in risk taking behaviour of boys and girls (Ginsburg and Miller 1982; Block 1983;

Morrongiello and Dawber 1998; Morrongiello and Dawber 2000; Morrongiello and Hogg 2004). The findings of our study also show that parents describe boys as more boisterous and more likely to engage in rough play. Other studies have shown that listening is used as a supervision strategy for boys more than girls (Morrongiello, Ondejko et al. 2004). Our study found that listening was used in both areas for boys more than girls. As boys behaviour generally is more associated with increased risk taking and more active play, such as climbing, then this may explain the differential injury rates between boys and girls. Furthermore, boys left alone with listening used as the supervision strategy and who live in a disadvantaged area have a further elevated risk for injury.

Parents described the character and age of the child as shaping their supervision practices consistent with the findings of Ingram and Emond (2009). Child character was described rather than child gender, or a general awareness of the differential injury rates and risks associated with boys and girls. It may be that parents supervise boys and girls differently but do not perceive themselves as doing so.

It has been established that an older sibling can increase the injury risk to a younger sibling (Nathens, Neff et al. 2000). Other studies have reported that parents living in a disadvantaged area described that older siblings would provide some supervision of younger children (Ingram and Emond 2009). The lack of perception and awareness of 
this in St Ann's is important as they are not anticipating the potential injury risk of the older child to the younger child, which may further explain the differential injury rates.

The findings suggest that parents need to be made aware of the differences in the risk taking behaviour between boys and girls, the differential in injury rates and how boys and girls may require differential supervision, in order to have a preventative effect for unintentional injury. Parents living in disadvantaged areas, particularly those who are parenting alone, may require some education with regard to the injury risks of an older child to a younger sibling. Some parents may need additional support with child care.

Further qualitative research is needed to explore how parents combine watching and listening supervision strategies. This includes when, why and how parents use the different supervision strategies. Further research is also required to explore when, why and how different supervision strategies are used for boys and girls to help explain differential unintentional injury rates between boys and girls.

The findings indicate that parents describe the character of the child as shaping parental supervision strategies. Further research is required to determine whether factors such as parenting style, the maternal relationship with the child and responsiveness of the child to redirection effect parental supervision style. Specifically, research is required that includes parents living in disadvantaged areas.

The findings that parents who were parenting alone, were more likely to use older siblings as supervisors, and who were less likely to describe older siblings as an injury risk to the younger child, requires confirming and quantifying in further research. Factors such as lone parenting and a lack of support for child care require further research, in order to explain the relationship between parenting alone and supervision by older siblings.

\section{Conclusion}

This study found that parents in both areas perceived parental supervision as important in reducing childhood unintentional risks. Listening was used by parents in both areas but it was used more in the advantaged area. In both areas listening was used as a supervision strategy for boys more than girls. Parents described child character rather than child gender as shaping supervision practices. A difference was found with regard to older siblings; parents living in the advantaged area described older siblings as an injury risk to younger children. Parents in the disadvantaged area described older siblings as providing some supervision for younger children. Parents living in disadvantaged circumstances may face greater challenges with regard to supervision than parents living in advantaged circumstances and this may partly explain differences in injury risk.

Explanations for injury rates between the two areas are not due to differences in the parental perceptions of the importance of supervision in minimising injury risk. Parents in both areas describe the need to be constantly aware of where the child is and the activity that the child is engaged with. Furthermore parents in both areas describe how there is an increased injury risk to the child when the parents ability to supervise is impeded either by multi-tasking or distractions. Parents in both areas use listening as a supervision strategy. Listening was used more for boys than girls and parents living in Wollaton west used listening more than parents living in St Ann's. Parents living in both 
areas described how child character shaped supervision strategies. A difference exists between the areas in relation to older siblings and injury risk to the younger child. In St Ann's, where a mother was parenting alone, mothers described older siblings as providing some supervision to the younger child. There were no descriptions by mothers in St Ann's of older siblings as an injury risk to the younger child. In contrast in Wollaton west mothers described older children as an injury risk to the younger child. This difference may provide some explanation for differences in injury rates between the two areas.

Further qualitative research is needed to explore how parents combine watching and listening supervision strategies. This includes when, why and how parents use the different supervision strategies. Further research is also required to explore when, why and how different supervision strategies are used for boys and girls to help explain differential unintentional injury rates between boys and girls. The findings indicate that parents describe the character of the child as shaping parental supervision strategies. Further research is recommended to determine whether factors such as parenting style, the maternal relationship with the child and responsiveness of the child to redirection effect maternal supervision style. Further research is required that specifically includes parents living in disadvantaged areas. The findings that parents living in circumstances of disadvantage and who were parenting alone, were more likely to use older siblings as supervisors, and who were less likely to describe older siblings as an injury risk to the younger child, requires confirming and quantifying in further research. Factors such as lone parenting and a lack of support for child care require further research, in order to explain the relationship between living in disadvantaged circumstances and supervision by older siblings.

What this study adds: Few qualitative studies have investigated maternal perceptions of supervision to reduce unintentional injury, within the home, by comparing two different socio-economic groups. Exploring maternal perceptions in this way has teased out and highlighted differences in order to generate possible explanations for differential injury rates.

Acknowledgements: The authors acknowledge the time given by health visitors to assist with recruitment to this study. The time given by parents to share their perspectives and experiences is also gratefully acknowledged. The study was funded by a scholarship from the School of Sociology and Social Policy, University of Nottingham.

Ethics: $\quad$ Ethical approval was provided by Nottingham research ethics committee Reference Number 06/Q2403/65. Organisational approval was granted by Nottingham Primary Care Trust. 


\section{REFERENCES}

ACAHC (2007). Better safe than sorry: preventing unintentional injury to children. A. C. a. H. Commission. London.

Block, J. (1983). "Differential premises arising from diffrential socialization of the sexes : Some conjectures." Child Development 19(4): 625-639.

Boles, R. E. and M. C. Roberts (2008). "Supervising Children During Parental Distractions." Journal of Pediatric Psychology 33(8): 833-841.

Bowling, A. (2002). Research methods in health. Milton Keynes, Open university.

Brannan, J. E. (1992). "Accidental Poisoning of Children: Barriers to Resource Use in a Black, LowIncome Community." Public Health Nursing 9(2): 81-86.

Brussoni, M., E. Towner, et al. (2006). "Evidence into practice: combining the art and science of injury prevention." Injury Prevention 12(6): 373-377.

Carr, S. (2005). "Peer educators--contributing to child accident prevention." Community Pract 78(5): 174-177.

DOH (2002). Preventing Injury - priorities for action. A report from the Accidental Injury Task Force to the Chief Medical Officer. London, Department of Health.

Edwards, P., I. Roberts, et al. (2006). "Deaths from injury in children and employment status in family: analysis of trends in class specific death rates." British Medical Journal 333(7559): 119-121.

Garling, A. and T. Garling (1995). "Mothers' anticipation and prevention of unintentional injury to young children in the home." Journal of Pediatric Psychology 20(1): 23-36.

Ginsburg, H. and S. Miller (1982). "Sex differences in children's risk taking behaviour." Child Development 53: 426-433.

Hendrickson, S. (2008). "Maternal Worries, Home Safety Behaviors, and Perceived Difficulties." Journal of Nursing Scholarship 40(2): 137-143.

Ingram, J. and A. Emond (2009). "Parents' perceptions of home injury risk and attitudes to supervision of pre-school children: a qualitative study in economically deprived communities." Primary Health Care Research \& Development 10(02): 98-108.

Kendrick, D., C. Mulvaney, et al. (2005). "Relationships between child, family and neighbourhood characteristics and childhood injury: a cohort study." Soc Sci Med 61(9): 1905-1915.

Morrongiello, B. A. (2005). "Caregiver supervision and child-injury risk: I. Issues in defining and measuring supervision; Il. Findings and directions for future research." Journal of Pediatric Psychology 30(7): 536-552.

Morrongiello, B. A., M. Corbett, et al. (2006). "Understanding unintentional injury-risk in young children I. The nature and scope of caregiver supervision of children at home." Journal of Pediatric Psychology 31(6): 529-539.

Morrongiello, B. A. and T. Dawber (1998). "Toddlers' and mothers' behaviors in an injury-risk situation: Implications for sex differences in childhood injuries." Journal of Applied Developmental Psychology 19(4): 625-639.

Morrongiello, B. A. and T. Dawber (2000). "Mothers' Responses to Sons and Daughters Engaging in Injury-Risk Behaviors on a Playground: Implications for Sex Differences in Injury Rates." Journal of Experimental Child Psychology 76(2): 89-103.

Morrongiello, B. A. and K. Hogg (2004). "Mothers' Reactions to Children Misbehaving in Ways That Can Lead to Injury: Implications for Gender Differences in Children's Risk Taking and Injuries." Sex Roles 50(1-2): 103-118. 
Morrongiello, B. A., T. J. Maclsaac, et al. (2007). "Older siblings as supervisors: Does this influence young children's risk of unintentional injury?" Social Science \& Medicine 64(4): 807-817.

Morrongiello, B. A., L. Ondejko, et al. (2004). "Understanding toddlers' in-home injuries: II. Examining parental strategies, and their efficacy, for managing child injury risk." Journal of Pediatric Psychology 29(6): 433-446.

Mull, D. S., P. F. Agran, et al. (2001). "Injury in children of low-income Mexican, Mexican American, and non-Hispanic white mothers in the USA: a focused ethnography." Social Science \& Medicine 52(7): 1081-1091.

Murphy, E., R. Dingwall, et al. (1998). "Qualitative research methods in health technology assessment: a review of the literature." Health Technology Assessment 2(16).

Nathens, A. B., M. J. Neff, et al. (2000). "Effect of an older sibling and birth interval on the risk of childhood injury." Inj Prev 6(3): 219-222.

O'Connor, T. G., L. Davies, et al. (2000). "Distribution of Accidents, Injuries, and Illnesses by Family Type." Pediatrics 106(5): e68.

Olsen, L., J. L. Bottorff, et al. (2008). "An ethnography of low-income mothers' safeguarding efforts." Journal of Safety Research 39(6): 609-616.

ONS (2009). Mortality Cause DR-08. Review of the Registrar General on Deaths by Cause Age and Sex in England and Wales. Newport UK, Office for National Statistics.

ONS (2011). "Table 2 Deaths Registration Summary Statistics. England and Wales 2011."

Patton, M. Q. (1980). Qualitative evaluation methods. London, Sage.

Pope, C., S. Ziebland, et al. (2000). "Qualitative research in health care: Analysing qualitative data." BMJ 320.

Roberts, H., S. J. Smith, et al. (1995). Children at risk? Safety as a social value. Buckingham, Oxford University Press.

Schwebel, D. C. and M. L. Bounds (2003). "The Role of Parents and Temperament on Children's Estimation of Physical Ability: Links to Unintentional Injury Prevention." Journal of Pediatric Psychology 28(7): 505-516.

Schwebel, D. C. and D. Kendrick (2009). "Caregiver supervision and injury risk for young children: time to re-examine the issue." Injury Prevention 15(4): 217-219.

Silverman, D. (2000). "Qualitative Research; a practical handbook."

Sparks, G., M. A. Craven, et al. (1994). "Understanding differences between high and low childhood accident rate areas: the importance of qualitative data." Journal of Public Health Medicine 16(4): 439-446.

Towner, E. (2002). The prevention of childhood Injury: Background paper prepared for the Accidental Injury Task Force. Newcastle, Department of Child Health.

Towner, E., T. Dowswell, et al. (2001). What works in preventing unintentional injuries in children and young adolescents? An updated systematic review. London, Health Development Agency. 